Artigo Original

\title{
Efeito da estimulação cortical na variável tempo de reação e performance hábil-motriz-cognitiva em jovens atletas de futebol
}

\author{
Sileno Martinho Silva Ribeiro Júnior ${ }^{1}$ \\ Márcia Maria dos Anjos Azevedo ${ }^{2}$ \\ Felipe Sampaio Jorge ${ }^{3}$ \\ Anderson Pontes Morales ${ }^{3}$ \\ Vernon Furtado da Silva ${ }^{1}$ \\ ${ }^{1}$ LANPEM. Universidade Castelo Branco, UCB, Rio de Janeiro, RJ, Brasil \\ ${ }^{2}$ Associação Brasileira de Ensino Universitário, UNIABEU, Belford Roxo, RJ, Brasil \\ ${ }^{3}$ Institutos Superiores de Ensino do Censa, Campos dos Goytacazes, RJ, Brasil
}

\begin{abstract}
Resumo: $O$ estudo verificou-se o efeito da estimulação cortical no tempo de reação e eficiência hábilmotriz-cognitiva em atletas de futebol, pré e pós-estimulação cortical $A$ amostra de $(\mathrm{N}=20)$ atletas masculino de futebol da categoria infantil. Os participantes foram divididos em 2 grupos, controle e experimental, sendo o grupo experimental submetido à estimulação. Foram realizadas 10 sessões, de 20 '. Os dados do teste foram tratados através de uma análise de variância paramétrica (ANOVA) two way. A média de acertos / pelo tempo de reação obteve ganho significativo para o grupo experimental quando comparada ao controlo no momento pós-teste $(\mathrm{P}<0.05)$. No grupo experimental obteve ganho significativo na melhora do tempo de reação quando comparado ao grupo controle $(p<0.05)$. No intra-grupos, o grupo que recebeu 0 treinamento combinado, obteve melhoras significativas comparados o pré e pós-teste $(p<0,05)$. Concluiu-se que $o$ treinamento combinado pode-se aprimorar a aprendizagem motora em diversas áreas de conhecimento e esporte.
\end{abstract}

Palavras-chave: Estimulação. Performance. Aprendizagem.

\section{Effect of the cortical stimulation in the variable reaction of time and skilled-motor-cognitive performance in young soccer athletes}

\begin{abstract}
The study was verified the effect of the cortical stimulation in the time of reaction and skilled motor cognitive efficiency in soccer athletes, before and cortical after stimulation the sample of $(\mathrm{N}=20)$ athletes masculine of soccer of the infantile category. The participants were divided in 2 groups, control and experimental, being the experimental group submitted to the stimulation. 10 sessions, of 20 '. The data originating from of the test were treated through a parametric variance analysis (ANOVA) two way. The average of successes / for the time of reaction obtained significant earnings for the experimental group when compared to the control in the moment after - tests $(P<0.05)$. In the experimental group obtained significant earnings in the improvement of the time of reaction when compared to the group controls $(p$ $<0.05)$. In the in groups, the group that it received the combined training, obtained significant improvements compared the before and after-test $(p<0,05)$. It was ended that the combined training the motor learning can be perfected in several knowledge areas and sport.
\end{abstract}

Key Words: Stimulation. Performance. Learning.

\section{Introdução}

O Ser humano possui grande poder de adaptação em sofrer mudanças em qualquer meio, usando para isso comandos através do cérebro sendo um sistema aberto de grande plasticidade que são alterados ao longo de nosso desenvolvimento, tendo uma enorme capacidade de aprendizagem e transformação de acordo com as mudanças ocorridas com o nosso processo evolutivo, onde existem diversos estudos comprovando a influencia da estimulação cortical para aprendizagem hábil-motriz e cognitiva.
Sabe-se que uma das particularidades de nosso cérebro é a sua atividade eletroquímica, um neurônio típico só leva 1 milissegundo (msec) para responder a um estímulo, quando ocorrem milhões de descargas de neurônios em harmonia estas descargas produzem custos elétricos "extensos", que criam ritmos chamados "ondas cerebrais" (SIEVER, 1999; CARDOSO et al, 2006). O ritmo alfa foi o primeiro ritmo de onda cerebral humana descoberto por Hans Berger em 1924, e vem sendo objeto de investigação constante, percebendo que as ondas alfas eram mais intensas quando o individuo mantinha-se 
com os olhos fechados, e diminui quando abria os olhos, e também quando estava em atividade mental, concluindo que era uma forma de funcional automático, e consciente $\underline{\text { (CARDOSO et }}$ al, 2006).

Os sucessos dos atletas dependem muito de vários fatores, como o psicológico, performance, da capacidade de concentração, percepção, diante de uma situação de dificuldade, como por exemplo, na hora de bater um pênalti que pode tirar um sonho de um atleta de ganhar um título, uma falta precisa, capacidade de raciocínio rápido em uma situação de jogo (DRAGANSKI et al, 2004) $O$ cérebro é responsável pela execução do processamento, com a mente sendo o produto por ele processado. Lima et al. (2004), diz que a velocidade de reação motora ou tempo de reação (TR), é o intervalo de tempo entre o momento da apresentação do sinal externo e o início da resposta muscular apropriada, já para Volchan et al. (2003) para preparar uma saída motora apropriada, o organismo tem que ser eficiente na codificação de estímulos relevantes 0 que também pode ser interpretado pela capacidade de reação a um estímulo num menor espaço de tempo possível segundo Flavell e Wellman (1977); Silva (2000), propõe que estas percepções associadas à capacidade cognitiva de alta ordem incluem vários níveis condicionais, como por ex: o conhecimento da tarefa a ser realizado, auto conhecimento de capacidade e dificuldade para realizar a tarefa, conhecimento de integração entre conteúdo aprendido e novos a serem empregados na realização da tarefa e conhecimento de estratégia a serem aplicadas.

Torna-se importante o desenvolvimento de métodos que possam condicionar os atletas a perceber e responder a estímulos relevantes num menor tempo possível, pois este tipo de habilidade: detectar, interpretar e tomar uma decisão correta num curto espaço de tempo pode, em muitos casos, ser o diferencial entre a vitória e a derrota em esportes em que se exige tomada de decisões rápidas. $O$ treinador faz com que cad desportista seja consciente de seus movimentos e estratégias, para que, desta maneira, atinja seu autocontrole e coordenação.

O treinamento por impulsos visuais e auditivos simultâneos que nos permite condicionar a atividade cortical para melhorarmos um determinado desempenho ou performance (HUTCHISON, 1986). Para Marques et al (2005) o treinamento por impulsos visuais e auditivos simultâneos significa a utilização de um sofisticado equipamento micro-processado (Brian machine) que tem como objetivo a mudança dos padrões corticais (ritmos do encéfalo) com a finalidade de melhorar seu rendimento em determinada atividade motor-cognitivo. Nesse tipo de treinamento processam em um âmbito puramente cognitivo e são realizadas por estruturas.

Baseado nestas perspectivas 0 presente estudo tem como objetivo investigar o Padrão de estimulação cortical na melhora da performance hábil-motriz-cognitiva no fundamento chute ao gol em jovens atletas futebol, pré e pós-estimulação cortical através de ondas alfas alta, verificando o número de acerto dentre três níveis de dificuldade.

\section{Métodos}

O voluntário apresentou-se com short e com o membro inferior desnudo, sendo feito o teste da estratégia de equilíbrio do passo (VICKERS, 2004), para definição do membro dominante, o membro não dominante. Os participantes foram levados a um campo de futebol profissional, onde foram escolhidos pelo treinador 20 jogadores de maior habilidade técnica e tática, dentre as posições de meio-campo e ataque pertencentes à categoria infantil com mais de dois ano no clube, posteriormente foram escolhidos pós o pré- teste os, 10 atletas os que seriam do grupo (A) experimental que obtiveram a pior performance de acerto e os 10 do grupo(B) controle. Todos os participantes do estudo foram testados em formato individual. Após chegarem ao local do teste, estes foram instruídos sobre as tarefas a serem cumpridas por cada um deles. Um período breve de adaptação foi dado a eles. Essa adaptação se reduziu a três tentativas em cada tarefa e uma explicação detalhada sobre a aplicação específica antes do teste propriamente dita.

O equipamento a ser utilizado para analise do tempo de reação motora no fundamento chute a gol sicronicamente com o eletromiografo de superfície, foi feita de um compensado de madeira que estará cobrindo toda a estrutura do gol, dividida em 16 quadrantes, numerados de 1 a 16 divididos em partes iguais. Em cada quadrante estará conectado uma lâmpada de $60 \mathrm{w}$ de fácil visibilidade, onde o pesquisador terá um controle remoto capaz de ligar qualquer uma dessas lâmpadas. Uma vez a lâmpada acesa o atleta reagirá a esse estimulo tentando acertar 0 quadrante correspondente ao estimulo luminoso. 

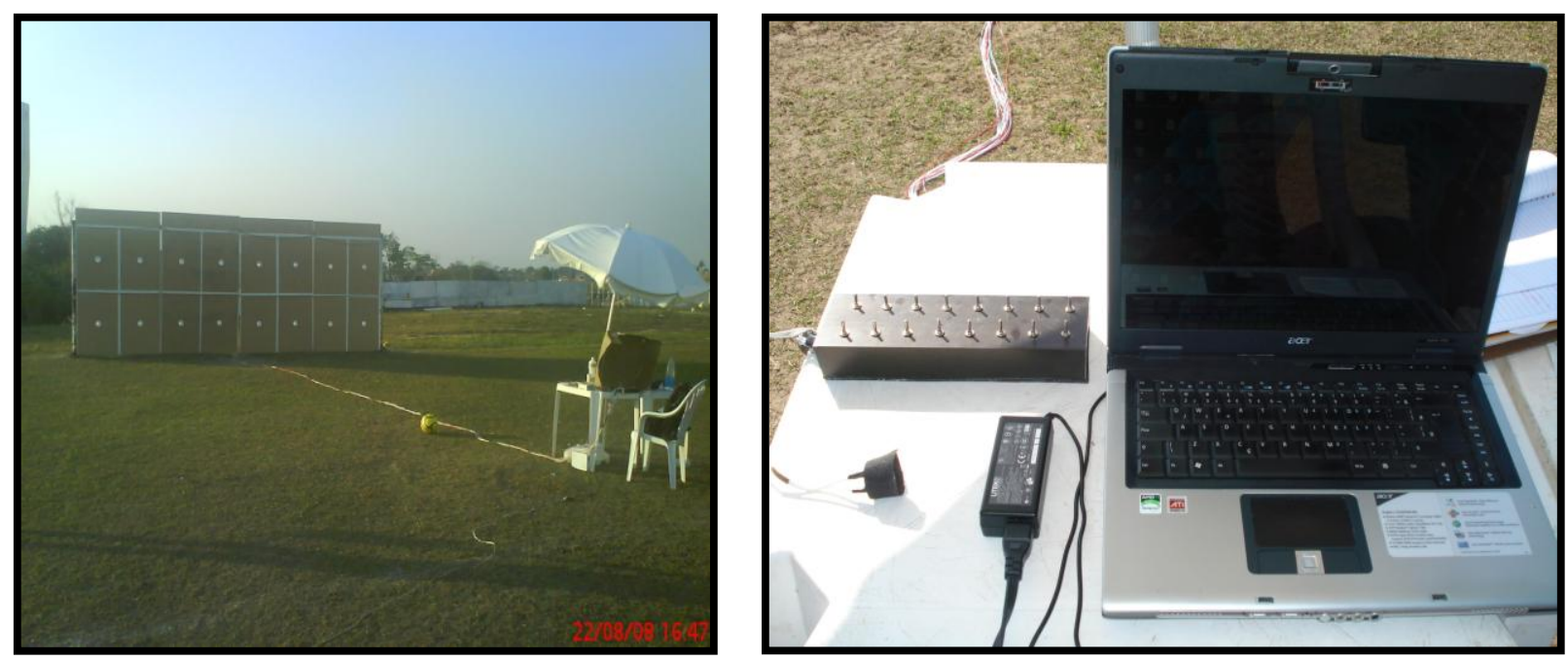

Figura 1: Equipamentos utilizados como o gol e diversos estímulos luminosos, eletromiógrafo de superfície e o posicionamento do atleta.

O equipamento a ser utilizado para analise do tempo de reação motora no fundamento chute a gol sicronicamente com o eletromiografo de superfície, foi feita de um compensado de madeira que estará cobrindo toda a estrutura do gol, dividida em 16 quadrantes, numerados de 1 a 16 divididos em partes iguais. Em cada quadrante estará conectado uma lâmpada de $60 \mathrm{w}$ de fácil visibilidade, onde o pesquisador terá um controle remoto capaz de ligar qualquer uma dessas lâmpadas. Uma vez a lâmpada acesa o atleta reagirá a esse estimulo tentando acertar 0 quadrante correspondente ao estimulo luminoso.

Os atletas foram posicionados a uma distancia 11 metros do gol sendo perna dominante a do chute, até que fosse dado o primeiro estimulo luminoso emitido pelos quadrantes no gol, e assim serão instruídos a se concentrar e tentar acertar o alvo, sendo o mais preciso possível, sendo que cada atleta irá realizar 9 chutes divididos em 3 para cada nível de dificuldade: níveis fáceis, médios e difíceis. Os indivíduos foram solicitados para participarem espontaneamente dos testes, que a eles e seus respectivos responsáveis foi explicado toda a metodologia que seria utilizada durante a coleta dos dados, garantindo que não haveria nenhum dano físico ou psicológico. Através da autorização de todos que participaram do processo de seleção e testes deste estudo. Em um segundo momento foi utilizado um protocolo semiológico para verificar se os participantes poderiam utilizar o aparelho ou não. Foram utilizadas a sessões apropriadas para estimulação das ondas alfa (concentração) com duração de 20 minutos associado ao treinamento mental. Somente o grupo (A) realizou o treinamento, no laboratório de pesquisa com uma sala ampla, com iluminação ambiente e silenciosa do Rio Branco Futebol Clube, onde o atleta será instruído a ficar de olhos fechados deitado devidamente relaxados, onde foram realizadas 10 sessões intervaladas, sendo dia sim dia não durante 20 minutos cada. Em um terceiro momento foi realizado o pós-teste sendo com os 20 atletas, e verificando a melhor performance de acertos e tempo de reação do grupo experimental e o controle.

\section{Resultados}

Os valores apresentados no gráfico abaixo são referentes ao percentual de acertos no pré e pós pontencialização cerebral do grupo experimental representado pelo gráfico branco, e o grupo controle representado pelo gráfico escuro.

Podemos observar na figura 2 que o grupo experimental que no momento pré-estimulação que era a pior performance, no momento pósestimulação passou a ser a melhor performance, dentre as três fases caracterizando uma melhora evidente para o tempo de reação motora e performance de acertos nos quadrantes luminosos no fundamento chute a gol dos atletas que sofreram a intervenção por luz e som associado à imagética. 


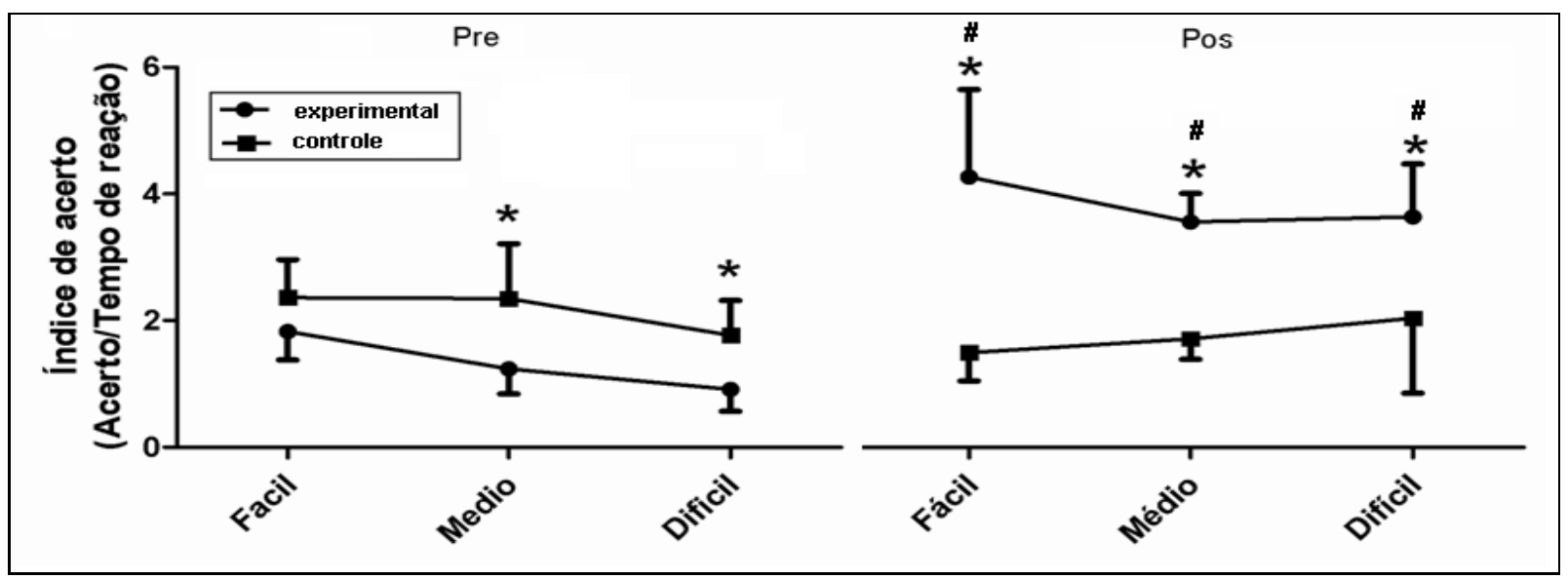

Figura 2. Índice de acerto (Acerto/Tempo de reação). A figura ilustra o Índice de acerto que é obtido através da divisão do Acerto pelo Tempo de reação, nos grupos experimental e controle. ( $\left.{ }^{*}\right)$ Indica diferença entre o grupo experimental e controle, $\mathrm{p}<0.05$. (\#) Indica diferença do grupo experimental nos momentos pré e pós, $\mathrm{p}<0.05$. Dados expostos na forma de média $\pm \mathrm{DP}$

Observa-se na figura abaixo o índice do grupo controle (esquerda) e estimulado (direita) nos momentos pré e pós-treinamento. Nota-se que não há diferença estatística da média de acertos entre os momentos pré e pós intragrupo controle. Já no que se refere ao grupo experimental que foi submetido ao treinamento com luz, som e imagética, verifica-se diferença entre os momentos pré e pós-estimulação intragrupo experimental.

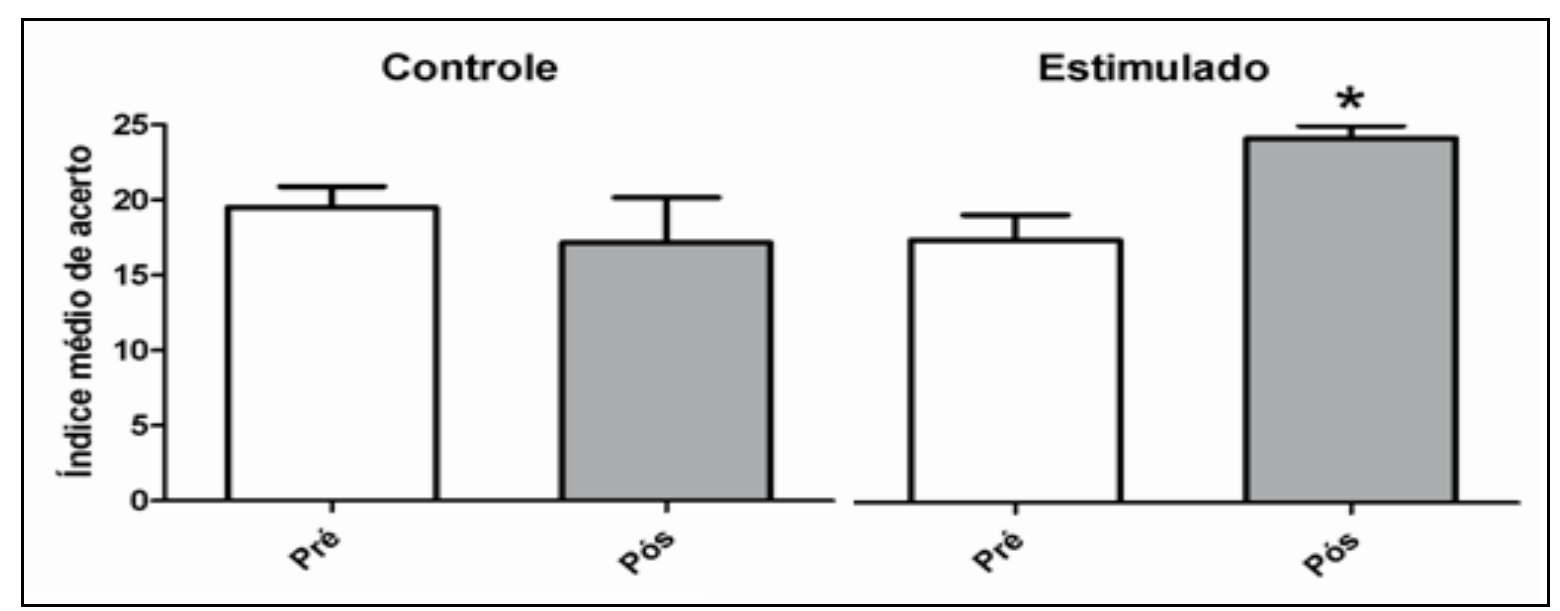

Figura 3. Performance média de acerto. Índice adquirido levanta em consideração acerto e erros nos quadrantes. Verifica-se o índice do grupo controle (esquerda) e estimulado (direito) nos momentos pré e após o treinamento. $\left({ }^{*}\right)$ Indica diferença após o treinamento com estimulação, $p<0.05$. Dados expostos na forma de média \pm DP

De acordo com a tabela 1 visualiza-se que houve um aumento na performance de acertos no grupo experimental quando comparado ao momento pré, onde na fase fácil, a média de acertos foi de $6.63 \pm 0.52$ para $8.13 \pm 0.64$, na fase média de $5.38 \pm 1.19$ para $8.13 \pm 0.35$ e na faz difícil de $5.38 \pm 1.51$ para $7.88 \pm 0.64$. Observase também um menor no desvio padrão do grupo experimental no momento pós quando comparado ao momento pré. No que se refere ao grupo controle podemos notar que indica uma diminuição da performance da média de acertos no momento pré quando comparado ao momento pós diante das fases fácil e média, onde na fase fácil a média foi de $6.83 \pm 1.17$ para $5.00 \pm 1.41$ na média foi de $7.33 \pm 0.52$ para $6.17 \pm 0.75$ sendo $p<$ 0.05 , o que não acontece com a fase difícil onde a média de acertos foi de $5.33_{ \pm} 0.52$ para $6.00_{ \pm}$ 1.90 . 


\begin{tabular}{|c|c|c|c|c|c|c|c|}
\hline \multicolumn{8}{|c|}{ PERFORMANCE DE ACERTOS } \\
\hline & & \multicolumn{3}{|c|}{ Pré } & \multicolumn{3}{|c|}{ pós } \\
\hline & & fácil & Médio & difícil & fácil & médio & difícil \\
\hline & media & 6.63 & 5.38 & 5.38 & 8.13 * & $8.13 *$ & 7.88 * \\
\hline Experimental & DP & 0.52 & 1.41 & 1.19 & 0.64 & 0.35 & 0.64 \\
\hline \multirow{2}{*}{ Controle } & media & 6.83 & 7.33 & 5.33 & $5.00^{\dagger}$ & $6.17^{\dagger}$ & 6.00 \\
\hline & DP & 1.17 & 0.52 & 0.52 & 1.41 & 0.75 & 1.90 \\
\hline
\end{tabular}

Tabela 1. Performance específica de acertos. Verifica-se as performances de acerto nos níveis fácil médio e difícil. $\left(^{*}\right)$ Indica aumento da performance no grupo experimental quando comparado ao momento pré $(p<0.05)$. ( $\dagger)$ Indica diminuição da performance no grupo controle quando comparado ao momento pré $(p<0.05)$.

Verifica-se na figura 4 o grupo controle e experimental nos testes fácil, médio e difícil; pré e póstreinamento. Pode-se notar que quando se refere ao grupo controle nota-se uma real diferença no tempo de reação diante dos três níveis de dificuldades no momento pré-teste, onde o grupo controle neste momento obteve melhores resultados quando comparados ao grupo experimental.

Nota-se que os atletas do grupo experimental demoraram mais para reagir ao estimulo luminoso emitido pelo equipamento tendo um tempo de reação maior. Podemos observar que o grupo experimental no momento pós-teste que realizou o treinamento por luz e som e imagética, melhorou o seu tempo de reação quando comparado ao pré-teste e quando comparado ao grupo controle, mostrando uma melhora da capacidade de estimulo resposta. Podemos notar também uma diferença comparando-se controle com experimental, pós-estimulação. De acordo com a figura abaixo se nota uma diferença estatística comparando-se o grupo experimental após o treinamento com ele mesmo no momento pré-treinamento.

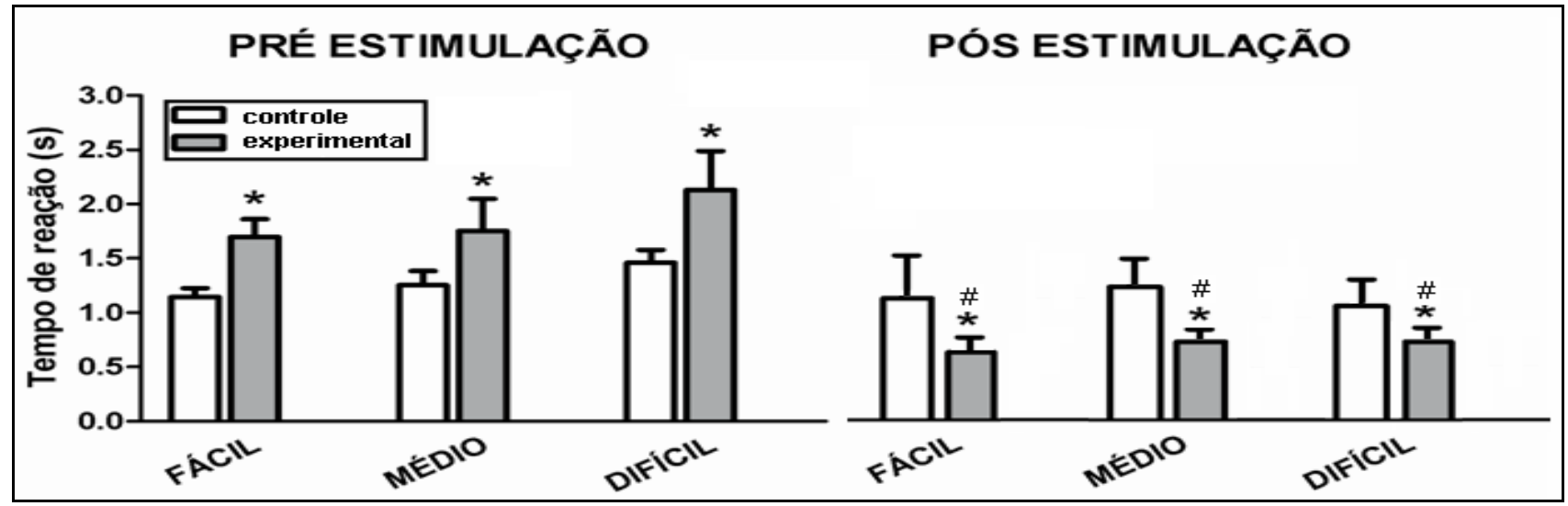

Figura 4. Tempo de reação. A figura indica o tempo de reação ao estímulo luminoso acionado sincronicamente com a EMG. Verifica-se o grupo controle e experimental nos testes fácil, médio e difícil; pré e após o treinamento. $\left(^{*}\right)$ Indica diferença comparando-se controle com experimental, $p<0.05$. (\#) Indica diferença comparando-se o grupo experimental após o treinamento com ele mesmo no momento pré treinamento, $p<0.05$. Dados expostos na forma de média \pm DP.

O gráfico da figura 5 nos mostra o índice de acerto pelo tempo de reação do grupo controle e experimental nas fases fácil, média e difícil. Verifica-se que quando se refere ao grupo controle não se encontra resultados estatisticamente significativo na performance total do atleta quando comparado ao momento pré e pós de cada nível de dificuldade. Conforme os gráficos revela, podemos perceber que quando comparado ao grupo que realizou o treinamento por estimulação por luz e som e imagética, que houve diferença significativa do momento pós quando comparada ao momento pré na fase fácil, média e difícil do chute os quadrantes no gol. 


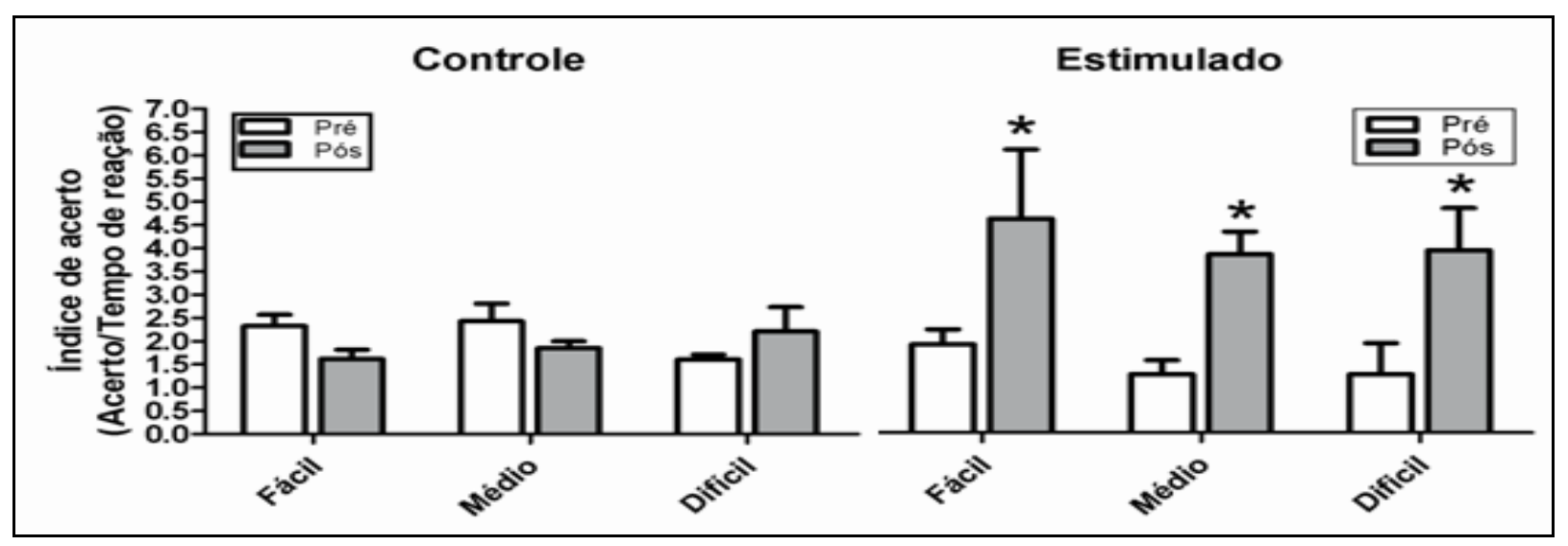

Figura 5. Índice de acerto (Acerto/Tempo de reação). A figura ilustra a divisão entre o índice de acerto que é obtido pelo tempo de reação nos grupos experimental e controle no momento pré e pós-estimulação cortical. $\left.{ }^{*}\right)$ Indica a diferença entre o grupo experimental (estimulado) no momento pré e pós onde $p<0.05$.

Verifica-se na figura 6 o total do índice de acertos pelo tempo de reação do grupo controle (esquerda do gráfico) no momento pré, do grupo controle quando comparado com o momento pós, não se obteve diferença significativa entre eles. Já quando comparado ao grupo estimulado (direita do gráfico), pode-se observar que há diferença entre o momento pré e pós-estimulação por luz e som associado à imagética do grupo experimental, evidenciando uma melhora na performance de acertos no fundamento chute ao gol de atletas de futebol da categoria infantil dantes dos testes

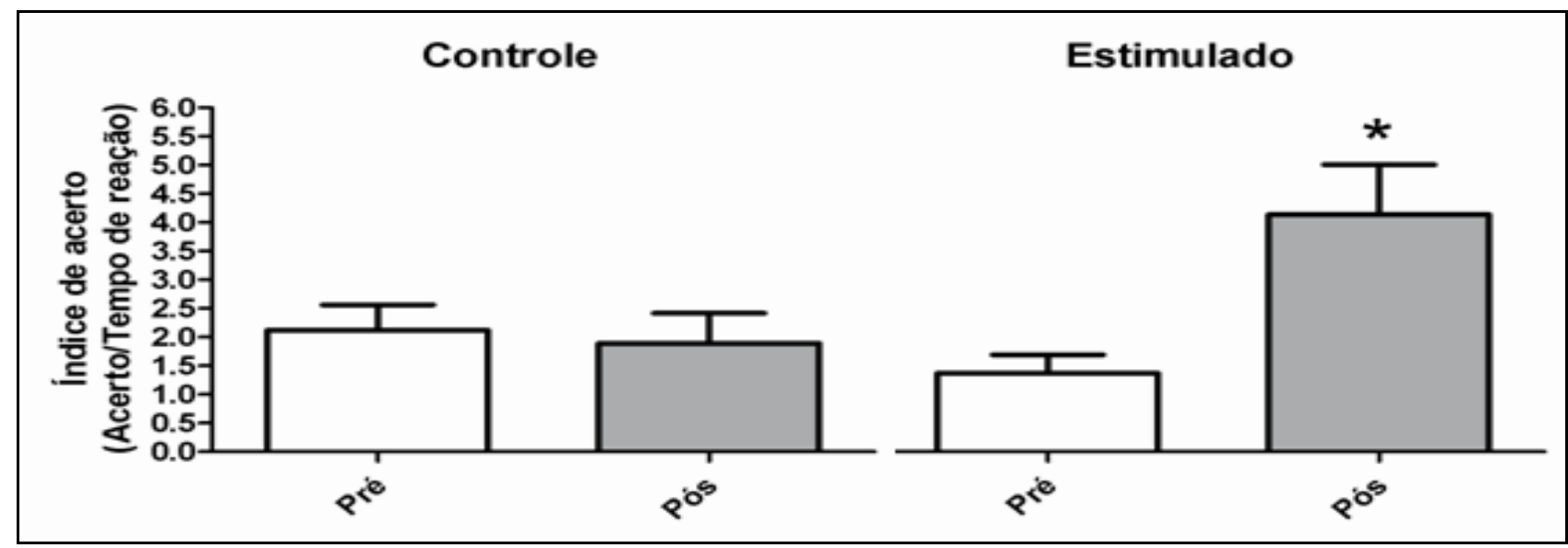

Figura 6. Índice de acerto (Acerto/Tempo de reação). A figura ilustra a divisão entre o índice médio de acerto que é obtido pelo tempo de reação nos grupos experimental e controle no momento pré e pós estimulação cortical. Verifica-se o índice do grupo controle (à esquerda) e do grupo estimulado (a direita) no momento pré e pós o treinamento. $\left({ }^{*}\right)$ Indica diferença após o treinamento no momento pré e pós sendo $p<0.05$. Dados expostos na forma de média \pm DP.

$\mathrm{Na}$ tabela 2 estão os resultados da analise descritiva, onde podemos ressaltar que houve uma variabilidade maior referente ao tempo de reação para o grupo controle e experimental no momento pré-estimulação com luz e som associado à imagética. Podemos verificar que no grupo controle nível fácil obteve-se uma variância de $0.07+0.26$, no nível médio $0.20+0.45$ e no nível difícil $0.06+0.25$, estando mais distantes dos valores mínimo e máximo tendo variações de valores. Observa-se que da mesma forma acontece com o grupo experimental onde podemos notar que os valores também variaram, onde na fase fácil sua variabilidade é de $0.18+$ 0.43 , no nível médio $0.13+0.36$ e no nível difícil $0.22+0.47$.

$\mathrm{Na}$ tabela 3 estão os resultados da analise descritiva, onde podemos observar que houve uma variabilidade menor do grupo experimental referente ao tempo de reação quando comparado ao grupo controle. Podemos notar que no grupo controle nível fácil obteve-se uma variância de $0.15 \pm 0.39$, no nível médio $0.7 \pm 0.25$ e no nível difícil $0.06 \pm 0.25$, estando 0 grupo controle heterogêneo quanto comparado ao grupo 
experimental. Já no grupo experimental podemos notar que os valores variam menos, onde na fase fácil sua variabilidade é de $0.02 \pm 0.12$, no nível médio $0.01 \pm 0.10$ e no nível difícil $0.02 \pm 0.14$, estando o grupo que realizou o treinamento por indução visual e auditiva associada a imagética com menor variância entre os valores mínimo e máximo mais estando mais próximos, o que nos indica um maior sincronismo no chute entre os atletas que sofreram a estimulação cortical quando comparado ao grupo não estimulado.

TEMPO DE REAÇÃO PRÉ-ESTIMULAÇÃO

\begin{tabular}{lccc|ccc}
\hline & \multicolumn{3}{c|}{ CONTROLE } & \multicolumn{3}{c}{ EXPERIMENTAL } \\
& FÁCIL & MÉDIO & DIFÍCIL & FÁCIL & MÉDIO & DIFÍCIL \\
\hline MÉDIA & 1.21 & 1.26 & 1.51 & 1.61 & 1.48 & 1.80 \\
MEDIANA & 1.19 & 1.25 & 1.48 & 1.66 & 1.50 & 1.77 \\
MIN & 0.91 & 0.73 & 1.25 & 1.00 & 1.04 & 0.99 \\
MÁX & 1.52 & 1.97 & 1.93 & 2.23 & 1.96 & 2.68 \\
VARIÂNCIA & 0.07 & 0.20 & 0.06 & 0.18 & 0.13 & 0.22 \\
DP & 0.26 & 0.45 & 0.25 & 0.43 & 0.36 & 0.47 \\
\hline
\end{tabular}

Tabela 2. Valores da estatística descritiva do tempo de reação. A tabela representa os valores de tendência central e os valores descritivos no momento pré-estimulação cortical. Observe que o grupo experimental e controle tem maior variância e valores de min e max mais distantes, o que indica uma maior variação de valores.

\begin{tabular}{lccc|ccc}
\hline \multicolumn{7}{c}{ TEMPO DE REAÇÃO PÓS-ESTIMULAÇÃO } \\
\hline & \multicolumn{3}{c}{ CONTROLE } & \multicolumn{4}{c}{ EXPERIMENTAL } \\
& FÁCIL & MÉDIO & DIFÍCIL & FÁCIL & MÉDIO & DIFÍCIL \\
\hline MÉDIA & 1.13 & 1.23 & 1.05 & 0.63 & 0.73 & 0.72 \\
MEDIANA & 0.98 & 1.28 & 1.14 & 0.68 & 0.70 & 0.75 \\
MIN & 0.72 & 0.79 & 0.66 & 0.38 & 0.60 & 0.48 \\
MÁX & 1.81 & 1.45 & 1.35 & 0.74 & 0.90 & 0.92 \\
VARIÂNCIA & 0.15 & 0.07 & 0.06 & 0.02 & 0.01 & 0.02 \\
DP & 0.39 & 0.26 & 0.25 & 0.12 & 0.10 & 0.14 \\
\hline
\end{tabular}

Tabela 3. Valores da estatística descritiva do tempo de reação. A tabela representa os valores de tendência central e os valores descritivos do momento pós-estimulação cortical. Observe que o grupo experimental tem menor variância e valores de min e max mais próximos, o que indica uma menor variação de valores

\section{Discussão}

No presente estudo foi observado que ouve uma melhora significativa da performance motora de acertos ao quadrante luminoso e conseqüentemente do tempo de reação, dos atletas amadores que receberam a intervenção por estimula áudio-visual e imagética quando comparados com o grupo controle.

Conforme a figura 2 revela, percebe-se que no momento pré-teste, o grupo controle obteve uma melhor performance de acertos quando comparada ao grupo experimental sendo $\mathrm{P}<0.05$. Percebe-se que o nível fácil, para o grupo controle e experimental não se obteve resultados significativos entre os grupos. Acredita-se que a capacidade de execução da tarefa, era de baixa ordem cognitiva, pois os atletas já tinham o conhecimento da tarefa a ser realizado, e até mesmo os quadrantes específicos que iriam ter que acertar. Vários autores enfatizam que a performance em um desporto pode estar associada à combinação de conhecimentos cognitivos ocorrido de experiência passada e a capacidade desportiva em utilizar sua habilidade motora com mais facilidade (OLIVEIRA et al, 2006). Corroborando com esta idéia Amaral e Silva (2006), define metacognição como o produto cognitivo, ou seja, ao conhecimento de que determinado conceito práticas e habilidades já são dominadas enquanto outras ainda não 0 foram, reconhecendo o que se é (ou não) capaz de alcançar a compreensão dos processos cognitivos, ou seja, pelo qual o pensamento e as funções superiores, atenção, memória , percepção, raciocínio, atuariam na resolução do problema.

Existem outras funções cognitivas que auxiliaram os atletas a terem um melhor desempenho, como a orientação viso-espacial. A posição que os atletas se encontravam, era mais 
central aos quadrantes, conseqüentemente a orientação viso-espacial era menos solicitada, fatores esses que exigiam menos de sua capacidade cognitiva o que pode explicar a melhor performance entre os dois grupos diante dessa tarefa. Podemos perceber ainda na (figura 2), pós-teste, que quando comparado os grupos, controle $\mathrm{x}$ experimental, o grupo controle que antes era a melhor performance virou a pior e 0 grupo experimental que sofreu intervenção com estimulo áudio-visual com ondas alfas $11 \mathrm{~Hz}$ durante 20 minutos, em um período de 2 semanas totalizando 10 sessões e imagética agora é a melhor performance sendo $p<0.05$, dentre os três níveis de dificuldade.

O gráfico da (figura 4), mostra dados expostos na média \pm Desvio Padrão e nota-se uma real diferença no tempo de reação diante dos três níveis de dificuldades no momento pré-teste, onde o grupo controle neste momento obteve melhores resultados quando comparados ao grupo experimental sendo $(p<0.05)$. Podemos perceber que quando comparado ao grupo que realizou o treinamento por estimulação áudio visual e imagética, houve diferença significativa do momento pós quando comparada ao momento pré na fase fácil, média e difícil do chute aos quadrantes no gol sendo $(p<0.05)$. Segundo Oliveira et al. (2004), o tempo de reação é umas das medidas de resultado de desempenho mais utilizadas, visto que, indica o resultado ou efeitos do desempenho de uma habilidade motora. Já para Volchan et al. (2003), para preparar uma saída motora apropriada o organismo tem que ser eficiente na codificação de estímulos vindo do meio externo. Esses resultados se tornam importante, pois, umas das características do jogo de futebol é a velocidade com que eles precisam responder diante de uma jogada. $O$ atacante por ex: quando encontra-se diante o goleiro. Nesse momento quanto mais rápido for o estímuloresposta, mais eficiente será no momento do chute, como conseqüências, maiores serão suas possibilidades de obter sucesso na finalização. Como é o caso de craques Brasileiro como Ronaldo, Kaká, Robinho, Romário, ou seja, atletas com um potencial Metacognitivo.

Podemos observar nos dados da estatística descritiva da (tabela 2), onde percebe-se que 0 grupo controle no momento pré-teste, por mais que na (tabela 1), mostre uma performance de acerto maior no nível médio, o tempo que eles demoraram para reagir foi maior, obtendo um maior acerto, mas obtiveram um processamento de informação mais lento, o que não foi o objetivo do presente estudo. Nota-se que no momento pré, que o grupo controle obteve um menor tempo de reação em relação ao experimental, nível fácil 1.21, médio 1.26, difícil 1.51. Já o grupo experimental no nível fácil 1.61, no médio 1.48 e difícil 1.80. No que se refere ao momento pósteste do grupo controle se obteve uma média no nível fácil de 1.13 no médio de 1.23 e no difícil de 1.51 já quando comparado ao grupo experimental (grupo estimulado), no momento pós-teste notase uma melhora do tempo de reação onde se obteve no nível fácil uma média de 0.63 no médio de 0.73 e no difícil 0.72 . Quando realizado a média + DP, como mostra na (figura 4), não se obtém diferença estatisticamente significativa quando comparada o momento pré-teste com o pós-teste do grupo não estimulado. Já quando comparado o momento pré com o pós do grupo experimental, fica evidente uma melhora significativa do tempo de reação dentre os três níveis de dificuldade $(P<0.05)$. Corroborando com esses achados vários estudos vem evidenciando que, em qualquer modalidade esportiva para que o atleta obtenha sucesso na realização da tarefa quanto mais concentrado, focado estiver o atleta, melhor será a capacidade de reação conseqüentemente sua performance o que dependerá de seu estado físico e emocional no momento da tarefa (VOLCHAN et al., 2003; LIMA et al., 2004; VICKERS, 2004).

É freqüente se observar à relação entre a capacidade de concentração e o desempenho do atleta em várias modalidades esportivas. Mesmos treinando muitas horas, erros são freqüentes. Um pênalti pode tirar o sonho de um atleta e da equipe de ganhar uma medalha de ouro; o tenista conhecido por realizar aquele saque indefensável pode apresentar falhas constantes durante o jogo. Diante da literatura pesquisada autores como, Da Silva et al. (2008); Lima et al. (2004), Silva (2000), segundo esses autores, o tempo de reação é um dos principais fatores que influenciam na melhora da performance motora no esporte, sendo decisivo entre a vitória e a derrota, desenvolver em um atleta a habilidade de perceber, interpretar e agir corretamente para um estímulo qualquer, em um menor tempo possível pode representar um trunfo importante na estratégia de ação, não só destas modalidades esportivas citadas no estudo como de qualquer outra modalidade de expressão competitiva. Não se pode esquecer que, de forma geral, a velocidade de processamento mental é fundamental, inclusive, para a vida comum social do homem. É freqüente se observar à relação entre a capacidade de concentração e o desempenho do atleta em várias modalidades esportivas. Mesmos treinando muitas horas, erros são freqüentes. Um pênalti pode tirar o sonho de um atleta e da equipe de ganhar uma medalha de ouro; o tenista conhecido 
por realizar aquele saque indefensável pode apresentar falhas constantes (DA SILVA et al., 2008).

Várias pesquisas demonstram avanços no que diz respeito ao desempenho no lance livre no basquete (VICKERS, 2004) ou no saque de tênis de mesa (RODRIGUES et al, 2002). Nesta técnica equipamentos acompanham a direção do olhar do atleta durante o lance livre, mostrando se ele focaliza ou não ao alvo.

Diversos estudos vêm sendo realizados sobre a performance física e metabólica do atleta, mas poucos estudos estão relacionando a performance motora ao treinamento mental, cognitivo, concentração, temporalidade, espacialidade, envolvendo o processo de atenção e a tomada de decisão o que por sua vez irá repercutir na capacidade de raciocino diante de sua estratégia dentro do jogo reagindo de forma rápida e eficiente o que pode ser o diferencial entre o atleta comum, e o craque o que mostra no presente estudo que podemos trabalhar o cérebro através de diversas ondas, de acordo com o objetivo, como preparar o atleta antes de uma partida importante, um treinamento com 0 equipamento de tempo de reação, melhorando a capacidade de estimulo/resposta, treinamento motor diante de diversos esportes.

Um estudo mostrou que a memorização de detalhes em crianças de cinco anos é maior do que nos adultos, já que nessas fases estão mais atentos a novos estímulos, corroborando com Weineck (2003) que diz que a faixa etária de maior desenvolvimento das qualidades cognitivas no futebol de campo, encontra-se na faixa etária dos 8 aos 16 anos. Segundo o mesmo autor (2003) este período de idade é onde ocorre um aumento da velocidade de maturação do córtex frontal responsável pelas principais ações como um centro de tomada de decisão e controle das ações voluntárias. Sendo assim foi de escolha realizar o estudo com jogadores da categoria infantil onde poderiam obter maiores resultados satisfatórios pelo fato de maior capacidade de aprendizagem em suas tarefas.

Temos assim que nos atentar para o fato de trabalhar com mais atenção a categoria de base, pois se o técnico, professor souber educar, ensinar e desenvolver de certa forma essa capacidade cognitiva desde as categorias de base, é provável que o jovem poderá apresentar um maior desenvolvimento sensório-motor, não somente para o esporte, mas para sua vida cotidiana, sendo um jovem mais ágil, com facilidade na escola, na sociedade, podendo desenvolver muito melhor do que aqueles que não receberam o treinamento. Muitas crianças são criadas dentro de redomas, apartamentos, poucos estímulos durante seu desenvolvimento e que poderá se tornar uma criança com dificuldades de relacionamento, no esporte na vida o que não é o caso de grandes atletas como Ronaldinho gaúcho, Romário, Robinho entre tantos e atletas da ginástica rítmica que tiveram a oportunidade de desenvolver diversas habilidades e informações físicas e cognitivas, com vários ambientes, criado nos campos, com várias crianças, diversos ambientes e não em escolinha esportivas.

Marques et al. (2005) compararam os efeitos da potencialização cerebral sobre a atividade cortical em grupos de diferentes preferências de processamento hemisférico e concluíram que a potencialização cerebral proporcionou efeitos positivos favorecendo o equilíbrio hemisférico, em um outro trabalho de estudo de caso desenvolvido por onde aplicaram a potencialização cerebral associada à prática física em um atleta de triathlon encontrando resultados significativos na melhoria da performance deste atleta em diferentes testes físicos e Cardoso et al. (2006) utilizaram com sucesso a potencialização cerebral como auxiliar na aprendizagem motora do jogo boliche em crianças, corroborando com 0 presente estudo, onde se obteve um resultado significante dentro dos três níveis de dificuldade no grupo que sofreu a intervenção da estimulação cortical com a luz e som, melhorando sua performance de acertos ao alvo. O que vale apenas ressaltar é que esse estudo não se resume somente à bola parada, mas para treinamento de uma forma geral, pois o equipamento feito na pesquisa poderá ser de grande valia o mundo do esporte onde o técnico poderia obter maiores resultados com treinamento específicos para tempo de reação e tomada de decisão diante do estimulo luminoso.

\section{Conclusão}

De acordo com o desenho metodológico empregado pode-se concluir que o treinamento com Brian machine (estimulação por luz e som) na onda alfa, programação na freqüência de $11 \mathrm{~Hz}$ associado a imagética neural causou um efeito positivo no tempo de reação e performance de acerto de praticantes de futebol, melhorando sua capacidade de raciocínio diante de uma situação problema, como uma batida de um pênalti, uma falta, e uma conclusão decisiva.

Conclui-se que o equipamento elaborado para quantificar, estimular e analisar o tempo de reação motora e performance de acerto no fundamente chute ao gol em jovens atletas 
juntamente com eletromiografo de superfície, foi eficaz para a analise dos resultados.

Houve melhora de acertos significantes para o grupo que utilizou a estimulação cortical e imagética mental, nos três níveis de dificuldades, obtendo melhora na performance do atleta em relação ao seu alvo.

Este resultado mostra que a intervenção com a estimulação por luz e som aliada à imagética realizado com o grupo experimental mostraramse relevante quando comparado com o grupo controle, evidenciando assim uma grande possibilidade para uma nova forma de aprendizagem motor-cognitivo, relacionada a gestos desportivos, podendo-se supor uma transferência destes ganhos para qualquer outro esporte que requeira melhoras em eficiência motora.

Considerando-se que não foram encontrados na literatura estudada trabalhos analisando a performance do atleta de futebol, com o equipamento de tempo de reação com estímulos luminosos ao gol, outros estudos poderão ser realizados, com atletas de handebol, categoria profissional de futebol, e até mesmo a utilização desse equipamento para setor pedagógico, e para treinamento de desportistas.

Torna-se importante, então, o desenvolvimento de métodos que possam condicionar os atletas a perceber e responder a estímulos relevantes num menor tempo possível, pois este tipo de habilidade: detectar, interpretar e tomar uma decisão correta num curto espaço de tempo pode, em muitos casos, ser o diferencial entre a vitória e a derrota em esportes em que se exige tomada de decisões rápidas.

\section{Referências}

AMARAL, V. M. M.; SILVA, V. F. Desenvolvimento cognitivo com aspectos no volibol. Tecnologia

Educacional, v. 167/16, p. 89-98, 2006.

Disponível em: http://abtbr.org.br/index.php?option=com facileforms\&ltem id=65 Acesso em: 23 jan. 2009

CARDOSO, F.B.; MACHADO, S.E.C.; DA SILVA, V.F. Estimulação Cerebral e Aprendizagem Motora: Efeitos no Aprendizado do Jogo de Boliche. Apresentado no III Congresso Científico Latino-Americano da FIEP, Foz do Iguaçu - PR/2006.

DA SILVA, V.F.; DE POLY, M.W.O.; RIBEIRO JÚNIOR, S.M.S.; CALOMENI, M.R.; PINTO, M.V.M.; SILVA, A.L.S.. Efeito agudo da estimulação cerebral, através de luz e som, no tempo de reação motora de jovens atletas.
Revista Digital - Buenos Aires. Ano 13 - № 120 - Maio de 2008. Disponível em: Disponível em: http://www.efdeportes.com/ Acesso em: 23 out. 2008.

DRAGANSKI, B.; GASER, C.; BUSCH, V.; SCHUIERER, G.B.U.; MAY, A.

Neuroplasticity:changes in grey matter induced by training. Nature, 427:311-2, 2004

FLAVELL, J.H.; WELLMAN, H.M. Metamemory. In: KAIL JUNIOR, R.V.; HAGEN, E.J.W. (Eds). Perspectives on the development of memory and cognition. Hillsdale: Lawrence Erlbaum, p. 3-33, 1977.

HUTCHISON, M. Megabrain: New Tools and Techniques for Brain Growth and Mind Expansion. New York: Ballantine Books. 1986.

LIMA, E.V.; TORTOZA, C.; ROSA, L.C.L.; LOPES-MARTINS, R.Á.B. Estudo da correlação entre a velocidade de reação motora e o lactato sanguíneo, em diferentes tempos de luta no judô. Revista Brasileira Medicina Esporte _ Vol. 10, № 5 - Set/Out, 2004.

MARQUES, L.J.; RIBEIRO, L.H.B.; ROCHA, D.; BARROS, G.; BORGES, D.; DIAS FILHO, D.L. ARAUJO, C.E.V.; Comparação dos efeitos da Potencialização Cerebral sobre a atividade cortical em grupos de diferentes preferências de processamento hemisférico. Artigo apresentado no congresso FIEP/Foz do Iguaçu 2005.

OLIVEIRA, F.A.; BELTRÃO, F.B.; SILVA, V.F.. Metacognição e Hemisfericidade em jovens atletas: Direcionamento para uma pedagogia de ensino desportivo. Rev. paul. Educ. Fís., São Paulo, 17(1): 5-15, jan./jun. 2004.

OLIVEIRA, Suzane; KELLER, Birgit; OKAZAKI, Fábio Heitor Alves; COELHO, Ricardo Weigert. A influência do treinamento mental (imagery) na performance de atletas de bodyboardg. Revista Digital Buenos Aires, v. 95, abril, 2006. Disponível em: Disponível em: http://www.efdeportes.com/ Acesso em: 23 out. 2008.

RODRIGUES, S.T.; VICKERS, J.N.; WILLIANS, A.M. Heead, eye and arm co- ordination in table tennis: An exploratory study. Journal of Sport Sciences, 20 (3): 171-186, 2002.

SIEVER, D. The Rediscovery of Áudio-visual Entrainmnent. 5 edição., Canadá , Comptronic Devices Limited, 1999.

SILVA, E.A.V. Metacognição: referências no nível de habilidade para jogar futebol. 2000. 
Dissertação (Mestrado) - Universidade Castelo Branco, Rio de Janeiro.

VICKERS, JN. The quiet eye: The difference between agood putter and a poor one, here's proof. Golf Digest, January, 96-ff, 2004.

VOLCHAN, Eliane; PEREIRA, Mirtes G; OLIVEIRA, Letícia de; VARGAS, Cláudia; MIRANDA, Janaína Mourão-; AZEVEDO, Tatiana Maia de; PINHEIRO, Walter Machado-; PESSOA, Luiz. Estímulos emocionais: processamento sensorial e respostas motoras. Revista Brasileira Psiquiatria, 25(Supl II):29-32, 2003

WEINECK, Jürgen, Treinamento Ideal, $9^{\mathrm{a}}$ ed. Editora Manoel, 2003

Esse artigo foi apresentado em Sessão Temática no VI Congresso Internacional de Educação Física e Motricidade Humana e XII Simpósio Paulista de Educação Física, realizado pelo Departamento de Educação Física do IB/UNESP Rio Claro, SP de 30/4 a 03/5 de 2009.

Endereço:

Sileno Martinho Silva Ribeiro Júnior Rua Thieres Cardoso, 59. Jockey Clube Campos RJ Brasil

28020-210

Telefone: (22) 9987.9730

e-mail: silenojunior@hotmail.com

Recebido em: 10 de fevereiro de 2009.

Aceito em: 03 de abril de 2009.

\section{(ब) $\Theta \Theta$}

Motriz. Revista de Educação Física. UNESP, Rio Claro, SP, Brasil - elSSN: 1980-6574 - está licenciada sob Licenca Creative Commons 